\title{
PERAN AUDIT INTERNAL TERHADAP PELAKSANAAN GOOD GOVERNANCE DI PERBANKAN SYARIAH
}

\author{
Muhammad Ardi \\ Sekolah Tinggi Agama Islam Negeri (STAIN) Watampone \\ Email: Muhammad_ardiii@yahoo.com
}

\begin{abstract}
Law 17 of 2003 and Law 1 Year 2004 triggered the renewal of state financial management. From both laws, the government through the Public Service Agency implements good governance in order to improve the performance and service of the community. This paper aims to examine the effect of internal audit for good governance either partially or simultaneously. Internal audits have a positive and significant impact on good governance both partially and simultaneously, indicating that both internal audits can improve the creation of good governance
\end{abstract}

\begin{abstract}
Abstrak: Undang-Undang 17 Tahun 2003 dan Undang-Undang 1 Tahun 2004 memicu pembaharuan manajemen keuangan negara. Dari kedua undang-undang tersebut, pemerintah melalui Badan Layanan Umum menerapkan good governance dalam rangka meningkatkan kinerja dan pelayanan masyarakat. Tulisan ini bertujuan untuk menguji pengaruh audit internal untuk tata pemerintahan yang baik baik secara parsial maupun secara simultan. Audit internal memiliki dampak positif dan signifikan terhadap pemerintahan yang baik baik secara parsial dan simultan, yang menunjukkan bahwa kedua audit internal dapat meningkatkan penciptaan pemerintahan yang baik.
\end{abstract}

Kata Kunci: Audit, Internal, Bank Syariah

\section{PENDAHULUAN}

Dalam kurun beberapa tahun terakhir, di Indonesia banyak bermunculan lembaga-lembaga keuangan yang bernafaskan Islam. Ini ditandai dengan banyak bermunculannya lembaga-lembaga Islam seperti Baitul Maal Wa Tamwil (BMT), Asuransi Syariah (takaful), Pegadaian Syariah, Lembaga Amal Zakat Infaq Shadaqah (LAZIS) dan yang paling sering mendapatkan perhatian adalah Bank Syariah.
Perkembangan ini meningkat dengan pesatbaik dalam segi nasabah, omzet, maupun asset-assetnya.Dari semua alasan yang dapat diterima akan adanya minat yang begitu besar pada bank syariah adalah adanya keyakinan bahwa dana yang mereka simpan telah melalui prosedur yang benar dan jauh dari hal-hal yang tidak bertentangan dengan syariat islam itu sendiri. Namun, dalam suatu masyarakat perbedaaan adalah sesuatu yang wajar, yang mana hal ini direspon dengan adanya sebagian masyarakat yang memiliki pendapat 
berbeda dalam menilai bank syariah, mereka yang umumnya mengetahui sifatdan karakteristik bank syariah cenderung untuk tidak bersikap proaktif dikarenakan mereka masih menganggap bahwa bank syariah yang ada sekarang masih belum sepenuhnya menjalankan syariat-syariat islam. Hal ini bisa terjadi karena mereka berpendapat bahwa sistem akuntabilitas pada bank syariah itu sendiri masih mengadopsi sistem akuntabilitas dari sistem konvensional yang masih baku, belum adanya teknis perhitungan dan penilaian yang benarbenar pasti untuk akuntansi syariah terutama dalam tataran teknis, dan yang terpenting, mereka berpendapat belum adanya jaminan bahwa bank syariah benar-benar telah menerapkan dan melaksanakan aturan syariah seperti yang diharapkan. Bagi kebanyakan umat Islam yang taat pada ajaran agamanya, mereka akan berusaha menghindari praktek "Riba" seperti yang biasa dilakukan pada praktek bank konvensional.

Terlepas dari banyaknya pendapat yang berbeda-beda, bank syari'ah merupakan suatu jalan keluar alternatif yang dapat dijadikan pilihan bagi umat muslim untuk menyimpan dana supaya tetap dapat memperoleh ketenangan dan ketentraman batin yang mana bank syariah ini menjanjikan sesuatu yang berbeda dengan apa yang ditawarkan oleh bank konvensional, yaitu adanya jaminan bahwa apa yang mereka jalankan sudah sesuai dengan pemenuhan syariat islam dan adanya suatu keyakinan bahwa apa yang telah dilakukan tidak melanggar prinsip syari'ah. Sehingga, agar nasabah tidak merasa ragu dalam menggunakan fasilitas bank syari'ah, maka banksyari'ah perlu menjaga kemurnian sistemoperasionalnya dari hal-hal yang mengakibatkan dilanggarnya prinsipprinsip syariah.

Selain sistem operasional yang sesuai dengan aturan syariah, penerapan good governance di perbankan syariah juga sangat ditekankan oleh masyarakat.nilai-nilai yang ada dalam good governance merupakan satu kesatuan yang tidak dapat dipisahkan dari aturan Islam. Oleh karena itu, pihak perbankan syariah dituntut masyarakat untuk melakukan tata kelola pemerintahan yang baik (good governance).Hal ini bertujuan untuk meningkatkan kepercayaan masyarakat terhadap kinerja pemerintah. Penerapan prinsip-prinsip good governance menjadi faktor penting untuk meningkatkan kinerja suatu organisasi.

Upaya untuk mewujudkan pemerintahan yang mampu melaksanakan praktik good governance yaitu adanya fungsi audit internal.Untuk mewujudkan kepemerintahan yang baik (goodgovernance), terdapat tiga aspek, yaitu pengawasan, pengendalian, dan pemeriksaan. Pemeriksaan (audit) merupakan kegiatan yang dilakukan oleh pihak yang memiliki independensi dan memiliki kompetensi profesional untuk memeriksa apakah hasil kinerja pemerintah telah sesuai dengan standar yang ditetapkan. Keberadaan audit internal untuk menjalankan fungsi 
pemeriksaan dapat mendorong terciptanya pelaksanaan tata kelola yang baik.

Berdasarkan uraian diatas, fokus tulisan ini membahas tentang pentingnya peran audit internal terhadap penerapan good governance di perbankan syariah.

\section{PEMBAHASAN}

\section{A. Bank Syariah}

Bank Syariah menjadi salah satu bagian dari Lembaga Keuangan Syariah (LKS) yang memiliki karakteristik berbeda dengan entitas konvensional. Perbedaan karakter tersebut mempengaruhi bentuk dan standar dalam kegiatan pengawasan lembaga bank syariah termasuk pelaksanaan auditnya. Pengawasan bank syariah yang berada dalam otoritas Bank Indonesia $(\mathrm{BI})^{1}$ dan Dewan Syariah Nasional (DSN) dilakukan dalam rangka menjaga kepatuhan terhadap prinsip-prinsip dan aturan syariah dalam operasional kegiatannya dan pelaporannya sesuai konsep perbankan syariah serta sesuai prinsip akuntansi bertema umum.2 Dalam hal ini, Dewan Pengawas Syariah (DPS) memiliki peran yang utama dalam pengendalian dalam aspek syariah dan auditor memiliki peran utama dalam menguji (examination) penyajian laporan keuangan yang fair. Adapun standar audit yang berlaku pada LKS termasuk bank Syariah adalah standar audit yang dikeluarkan dan disahkan oleh AAOIFI (Accounting and Auditing Organization for Islamic Financial Institutions) yang berada di Manama, Bahrain.

\section{B. Pengertian Audit Internal}

Menurut The Institute of Internal Auditor (IIA) sebagaimana yang dikutip oleh Patricia Saptapradiptaadalah aktivitas independen, keyakinan objektif dan konsultasi yang dirancang untuk memberikan nilai tambah dan meningkatkan operasi organisasi. Audit internal membantu organisasi mencapai tujuannya dengan menerapkan pendekatan yang sistematis dan disiplin untuk mengevaluasi dan meningkatkan efektivitas manajemen resiko, pengendalian dan proses tata kelola. ${ }^{2}$

\section{Tujuan dan Fungsi Audit Internal \\ Menurut Boynton, Johnson dan Kell} tujuan audit internal adalah untuk membantu manajemen organisasi dalam memberikan pertanggungjawaban yang efektif. ${ }^{3}$ Sedangkan menurut Mulyadi fungsi audit internal merupakan kegiatan penilaian yang bebas yang terdapat dalam organisasi, yang dilakukan dengan cara memeriksa akuntansi, keuangan, dan kegiatan lain, untuk memberikan jasa bagi manajemen dalam melaksanakan tanggung jawab mereka. ${ }^{4}$

\section{Standar Profesi Audit Internal}

a. Independensi Auditor Internal

Auditor internal harus objektif dan bebas dari pengaruh pihak manapun, seperti yang dikemukakan Tugiman, 5 sebagai berikut :

"Para auditor internal dianggap mandiri apabila dapat melaksanakan pekerjaannya secara bebas dan objektif. Kemandirian para pemeriksa internal dapat memberikan penilaian yang tidak memihak dan tanpa 
prasangka, hal mana sangat diperlukan atau penting bagi pemeriksaan sebagaimana mestinya. Hal ini dapat diperoleh melalui status organisasi dan sikap objektif pada auditor internal".

\section{E. Kemampuan Profesional}

Kemampuan profesional adalah: "tanggung jawab bagian audit internal dan setiap auditor internal. Pimpinan audit internal dalam setiap pemeriksaan haruslah menugaskan orang-orang secara bersama atau keseluruhan memiliki pengetahuan, kemampuan, dan berbagai disiplin ilmu yang diperlukan untuk melaksanakan pemeriksaan secara tepat dan pantas."

\section{F. Ruang Lingkup Pekerjaan}

Ruang lingkup pekerjaan meliputi pengujian dan evaluasi terhadap kecukupan dan keefektifan sistem pengendalian internal yang dimiliki oleh perusahaan dan kualitas pelaksanaan tanggung jawab. Ruang lingkup audit internal meliputi pemeriksaan dan evaluasi yang memadai serta efektivitas sistem pengendalian internal organisasi dan kualitas kinerja dalam melaksanakan tanggung jawab yang dibebankan.

\section{a. Pelaksanaan Kegiatan Pemeriksaan}

Pelaksanaan kegiatan pemeriksaan sebagai berikut: "Kegiatan pemeriksaan harus meliputi perencanaan pemeriksaan, pengujian dan pengevaluasian informasi, pemberitahuan hasil dan menindaklanjuti (follow up)."

\section{G. Good Governance \\ Good governance didefinisikan oleh} World Bank adalah Suatu penyelenggaraan manajemen pembangunan yang solid dan bertanggung jawab yang sejalan dengan prinsip demokrasi dan pasar yang efisien, penghindaran terhadap kemungkinan salah alokasi dan investasi, dan pencegahan korupsi baik yang secara politik maupun administratif, menjalankan disiplin anggaran serta penciptaan legal dan political framework bagi tumbuhnya aktivitas usaha.

Peraturan Pemerintah (PP) Nomor 101 Tahun 2000. menjelaskan pengertian kepemerintahan yang baik, yaitu: kepemerintahan yang mengembangkan dan menerapkan prinsip-prinsip profesionalitas, akuntabilitas, transparansi, pelayanan prima, demokrasi, efisiensi, efektifitas, supermasi hukum dan dapat diterima oleh seluruh masyarakat.

Good Corporate Governance adalah sebagai berikut :Good Corporate Governance (GCG) pada dasarnya merupakan suatu sistem(input, proses, output) dan seperangkat peraturan yang mengatur hubungan antara berbagai pihak yang berkepentingan (stakeholders) terutama dalam arti sempit hubungan antara pemegang saham, dewan komisaris, dan dewan direksi demi terciptanya tujuan perusahaan". 6

Adapun prinsip-prinsip good governance yang digunakan dalam penulisan ini di antaranya adalah $:^{7}$ 
a. Transparansi

Keputusan Menteri Negara BUMN No. 117/M-MBU/2002 pasal 3 mendefinisikan transparansi sebagai keterbukaan dalam melaksanakan proses pengambilan keputusan dan keterbukaan dalam mengemukakan informasi materiil dan relevan mengenai perusahaan. Selain itu, menurut Komite Nasional Kebijakan Governance (KNKG) menjelaskan bahwa transparansi (transparency) mengandung unsur pengungkapan (disclosure) dan penyediaan informasi secara tepat waktu,memadai, jelas, akurat, dan dapat diperbandingkan serta mudah diakses oleh pemangku kepentingan dan masyarakat.

b. Independensi

Keputusan Menteri Negara BUMN No. 117/M-MBU/2002 pasal 3 mendefinisikan independensi sebagai suatu keadaan di mana perusahaan dikelola secara profesional tanpa benturan kepentingan dan pengaruh/tekanan dari pihak manapun yang tidak sesuai dengan peraturan perundang-undangan yang berlaku dan prinsip-prinsip korporasi yang sehat. Selanjutnya menurut KNKG menjelaskan bahwa independensi mengandung unsur kemandirian dari dominasi pihak lain dan objektifitas dalam melaksanakan tugas dan kewajibannya.

c. Akuntabilitas

Keputusan Menteri Negara BUMN No. 117/M-MBU/2002 pasal 3mendefinisikan akuntabilitas sebagai kejelasan fungsi, pelaksanaan dan pertanggungjawaban organ sehingga pengelolaan perusahaan terlaksana secaraefektif. Selanjutnya menurut KNKG menjelaskan bahwa akuntabilitas (accountability) mengandung unsur kejelasan fungsi dalam organisasi dan cara mempertanggungjawabkannya.

d. Pertanggung Jawaban

Keputusan Menteri Negara BUMN No. 117/M-MBU/2002 pasal 3 : pertanggungjawaban sebagai kesesuaian di dalam pengelolaan perusahaan terhadap peraturan perundang-undangan yang berlaku dan prinsip-prinsip korporasi yang sehat. Selanjutnya menurut KNKG menjelaskan bahwa pertanggungjawaban yaitu perusahaan harus mematuhi peraturan perundangundangan serta melaksanakan tanggung jawab terhadap masyarakat dan lingkungan sehingga dapat terpelihara kesinambungan usaha dalam jangka panjang dan mendapatkan pengakuan sebagai good corporate citizen.

\section{H. Audit Internal di Bank Syariah}

Adanya pengawasan pada bank Syariah, audit internal dan corporate governance tidak berarti dapat menggantikan tugas manajemen bank dan tidak menjamin bank bebas dari krisis, kerugian maupun kebangkrutan. Hal tersebut disebabkan oleh beberapa faktor, antara lainhuman error, asymetric information, policy dan regulation yang kurang mendukung, dan reward dan punishment yang tidak jelas.

Oleh karena itu, Untuk mewujudkan pengawasan yang efektif dan berdaya guna hendaknya Bank Indonesia sebagai pemegang otoritas pengawasan 
perbankan di Indonesia mendukung sepenuhnya atas segala kegiatan pengawasan perbankan Syariah yang melibatkan DSN dan DPS dengan memberikan jaminan independen, insentif yang bernilai dan pertanggungjawaban yang jelas. Selain itu, Bank Indonesia bekerja sama dengan Kementrian Keuangan hendaknya membuat aturan dan kebijakan yang tegas mengenai reward dan punishment pada manajemen bank Syariah atas komitmennya menjalankan usaha perbankan berdasarkan prinsip dan aturan Syariah.

Adapun untuk kegiatan audit internal hendaknya dijalankan sesuai mekanisme yang benar dan disesuaikan dengan standar audit AAOFI yang berlaku pada seluruh Lembaga Keuangan Syariah (LKS). Segala kelemahan yang ada dalam sistem audit, seperti faktor human error, asymmetric information, dan lainnyahendaklah diminimalkan untuk mencapai hasil yang tepat. Disamping itu, adanya tata kelola perusahaan (corporate governance) hendaklah dimaksimalkan agar dapat memenuhi tanggung jawab sosial perusahaan terhadap masyarakat dan seluruh pihak yang memiliki kepentingan dengan perusahaan.

\section{Hubungan antara Audit Internal dengan Penerapan Good Governance di Bank Syariah.}

Secara lebih spesifik, organisasi mengandalkan fungsi audit internal untukmembantu memastikan bahwa proses manajemen risiko, lingkup pengendalian secara keseluruhan dan efektivitas kinerja dari proses usaha telah konsisten dengan ekspektasi manajemen. Fungsi audit internal saat ini tidak sekedar dituntut menemukan permasalahan namun sekaligus menjadi bagian dari solusi danmemberikan usulan perbaikan. Audit internal terlibat dan berperan aktif memantau aktivitas unit bisnis dan memberikan peran konsultatif dalam pelaksanaan prosesoperasi perusahaan. Dengan demikian, peran audit internal tidak hanya sebatas sebagai "detector" namun bisa lebih yaitu sebagai pencegah yang diharapkan mampu mendukung dan mendorong proses terwujudnya good governance.

Hubungan pengaruh peranan audit internal terhadap penerapan GCG telah dibuktikan dalam penelitian Wardoyo dan Lena. Hasil penelitiannya membuktikan bahwa peranan audit internal berpengaruh signifikan positif terhadap penerapan Good Corporate Governance di Perbankan Syariah. ${ }^{8}$

Hal tersebut dapat dibuktikan pula oleh Minarni, bahwa pengawasan pada bank syariah, audit syariah dan tata kelola perusahaan tidak berarti dapat menggantikan tugas manajemen bank dan tidak menjamin bank bebas dari krisis, kebangkrutan. Untuk itu Bank Indonesia hendaknya mendukung kegiatan pengawasan perbankan Syariah yang melibatkan DSNdan DPS. Audit syariah juga akan di jalankan sesuai Prosedur yang ada sedangkan tata kelolala perusahaan hendaklah 
dimaksimalkan agar memenuhi tanggung jawab sosial perusahaan. ${ }^{9}$

\section{PENUTUP}

Pengendalian internal berpengaruh secara signifikan dan positif terhadap pelaksanaan good governance. Selanjutnya, secara parsial audit internal dan pengendalian internal berpengaruh signifikan dan positif terhadap pelaksanaan good governance di Perbankan Syariah. Hal ini menjelaskan bahwa semakin efektif pelaksanaan audit internal dan semakin kuat pengendalian internal yang dibangun maka akansemakin tinggi pula pelaksanaan good governance di Perbankan Syariah.

Dengan demikian, penelitian ini secara keseluruhan menjelaskan perlunya fungsi audit internal dan pengendalian internal yang kuat secara beriringan menjadi kesatuan yang tidak terpisahkan dari prinsip-prinsip good governance. Kedua aspek tersebut penting dalam meningkatkan pelaksanaan good governance, dimana goodgovernance merupakan tuntutan dari masyarakat dan juga cerminan kinerja suatu organisasi.

\section{Catatan Akhir:}

${ }^{1}$ Sesuai dengan UU No. 21 tahun 2011 tentang Otoritas Jasa Keuangan (OJK), kewenangan mengawasi perbankan, termasuk bank syariah, secara bertahap akan dilakukan oleh OJK.

${ }^{1}$ Suryo Pratolo, Good Corporate Governance Dan Kinerja BUMN DiIndonesia: Aspek Audit Manajemen Dan Pengendalian Intern Sebagai Variabel Eksogen Serta Tinjauannya Pada Jenis Perusahaan. Simposium
Nasional Akuntansi X. Universitas Hasanudin Makassar, 2007.

${ }^{1}$ Boynton, William C., Johnson Raymond N,

Kell. Walter G. Modern Auditing.Edisi 7.Penerjemah Paul A. Rajoe, Gina Gania, Ichsan Setiyo Budi, Erlangga. Jilid I.Jakarta, 2006), hlm 25-25

${ }^{1}$ Mulyadi,Auditing (Buku kesatu.Edisi 6. Jakarta: Salemba Empat,2002),hlm 25

${ }^{1}$ Hiro. Tugiman,Standar Profesional Audit Internal. (Edisi Kelima, Kanisius: Yogyakarta, 2006),hlm. 20

${ }^{1}$ Suwanto Sutoyo dan E john Al dridge, Good Corporate Governance (tata kelola perusahaan sehat) cet I, Jakarta: PT. Damar Mulia. Pustaka, 2005, hlm.13.

${ }^{1}$ Achmad Arief Budiman, Good Governance pada Lembaga Ziswaf (Implementasi Perlibatan Pemangku Kepentingan dalam Pengelolaan Ziswaf . Semarang: Lembaga Penelitian, 2002.

${ }^{1}$ Wardoyo Trimanto S., dan Lena. 2010. Peranan Auditor Internal dalam Menunjang Pelaksanaan Good Corporate Governance Pada PT Dirgantara Indonesia. "Akurat Jurnal Ilmiah Akuntansi "No.3 Tahun ke-1 SeptemberDesember.

${ }^{1}$ Minarni, Konsep Pengawasan, Kerangka Audit Syariah dan Tata Kelola Lembaga Keuangan Syariah, “Jurnal Ekonomi Islam La_Riba" Volume VII No. 1 Juli 2013: Program Pascasarjana, Fakultas Ilmu Agama Islam, Universitas Islam Indonesia

\section{DAFTAR PUSTAKA}

Achmad Arief Budiman, Good Governance pada Lembaga Ziswaf (Implementasi Perlibatan Pemangku Kepentingan dalam Pengelolaan Ziswaf . Semarang: Lembaga Penelitian, 2002.

Boynton, William C., Johnson Raymond N, Kell. Walter G. Modern Auditing.Edisi 7. Penerjemah Paul A. Rajoe, Gina Gania, 
Ichsan Setiyo Budi, Erlangga. Jilid I.Jakarta, 2006.

Minarni, Konsep Pengawasan, Kerangka Audit Syariah dan Tata Kelola Lembaga Keuangan Syariah, "Jurnal Ekonomi Islam La_Riba" Volume VII No. 1 Juli 2013: Program Pascasarjana, Fakultas Ilmu Agama Islam, Universitas Islam Indonesia.

Mulyadi, Auditing, Buku kesatu. Edisi 6. Jakarta: Salemba Empat,2002.

Suryo Pratolo, Good Corporate Governance Dan Kinerja BUMN Di Indonesia: Aspek Audit Manajemen Dan Pengendalian Intern Sebagai Variabel Eksogen Serta Tinjauannya Pada Jenis Perusahaan. Simposium Nasional Akuntansi X. Universitas Hasanudin Makassar, 2007.
Sutoyo, Suwanto dan E john Al dridge, Good Corporate Governance (tata kelola perusahaan sehat) cet I, Jakarta: PT. Damar Mulia. Pustaka, 2005.

Tugiman, Hiro Standar Profesional Audit Internal. Edisi Kelima, Kanisius: Yogyakarta, 2006.

Wardoyo Trimanto S., dan Lena. 2010. Peranan Auditor Internal dalam Menunjang Pelaksanaan Good Corporate Governance Pada PT Dirgantara Indonesia. "Akurat Jurnal Ilmiah Akuntansi "No.3 Tahun ke-1 SeptemberDesember. 